
\title{
$\begin{array}{ll}\text { Research Square } & \begin{array}{l}\text { Preprints are preliminary reports that have not undergone peer review. } \\ \text { They should not be considered conclusive, used to inform clinical practice, } \\ \text { or referenced by the media as validated information. }\end{array}\end{array}$
}

\section{Evolution of GERD symptoms after bariatric surgery: A dose- response meta-analysis}

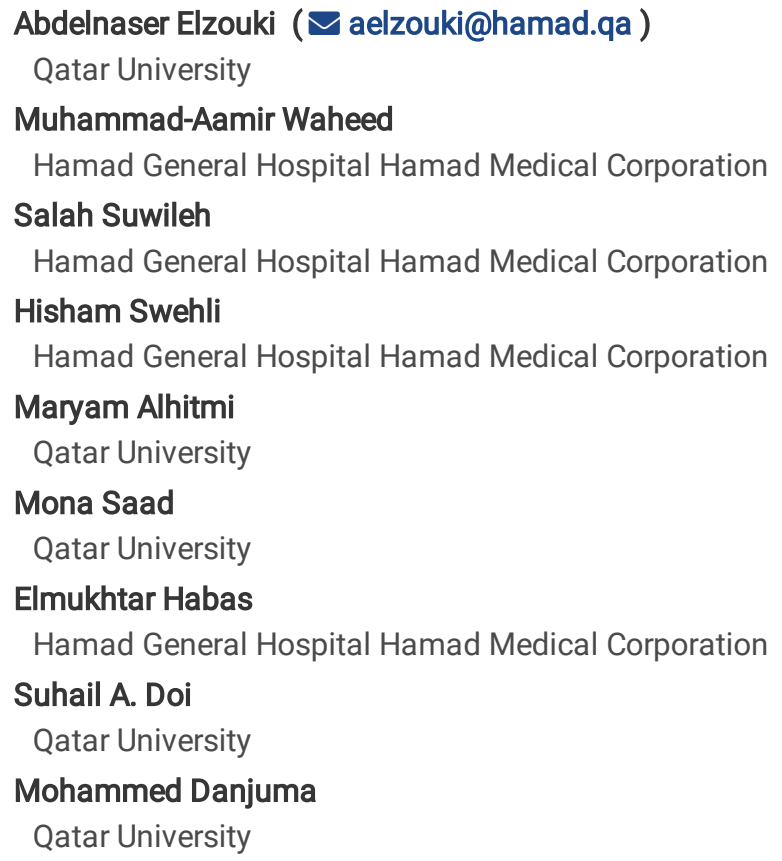

\section{Research Article}

Keywords: Bariatric surgery, Gastroesophageal reflux disease, Sleeve Gastrectomy, laparoscopic Roux-en-Y gastric bypass, dose-response meta-analysis

Posted Date: April 16th, 2021

DOI: https://doi.org/10.21203/rs.3.rs-408294/v1

License: (c) (i) This work is licensed under a Creative Commons Attribution 4.0 International License. Read Full License

Version of Record: A version of this preprint was published at Surgery Open Science on November 1st, 2021. See the published version at https://doi.org/10.1016/j.sopen.2021.11.006. 


\section{Abstract}

Importance Obesity is associated with increased prevalence of gastroesophageal reflux disease (GERD); with recent reports suggesting improvement in GERD symptoms and weight loss following bariatric surgical intervention. However, the exact impact of the type of bariatric surgery on the evolution of GERD symptoms have remained unexamined.

Objective To characterize the exact evolution of GERD symptoms, post bariatric surgery.

Data sources We systematically searched electronic databases (PubMed, EMBASE, Web of Science, and the Cochrane Library from inception to December 2018) for eligible studies that satisfy pre-specified inclusion criteria.

Study selection We included clinical trials of all designs (prospective and retrospective) that reported on GERD outcomes following Laparoscopic Sleeve Gastrectomy (LSG) or laparoscopic Roux-en-Y gastric bypass (LRYGB).

Data extraction and synthesis Two independent reviewers extracted relevant data based on the Preferred Reporting Items for Systematic Reviews and Meta-Analyses (PRISMA) guideline. Data were pooled using a random-effects model.

Main outcomes Symptomatic improvement in GERD symptoms following bariatric surgery

Results A total of 39 studies were analyzed and a robust-error meta-regression model was used to conduct a Dose-Response Meta-Analysis (DRMA) synthesizing data on 39 studies that reported GERD outcomes after bariatric surgery. Out of 43,994 patients who underwent either LSG $(\mathrm{N}=9,547$ patients) or LRYGB ( $N=34,447$ patients), 32.4\% experienced improvement in symptoms ( $95 \% \mathrm{Cl} 20.62$ to 45.45$)$; The DRMA demonstrated a window period of two years for sustained improvement after which symptoms began to recur in those that were asymptomatic.

Conclusion and relevance Bariatric surgery may improve GERD symptoms in obese patients who underwent LSG, however, the most favorable effect is likely to be found after Roux-en-Y gastric bypass surgery. The effects were not sustained and returned to baseline within 4 years.

\section{Introduction}

The burden of obesity is on the rise across different continents and populations around the world. ${ }^{1}$ Although different socio-demographic groups are involved, the burden appears more pronounced amongst adolescent and adult populations. ${ }^{1}$ Uncontrolled obesity has been associated with preventable morbidities across a wide range of cardiovascular and metabolic risks; these include cardiovascular disease, hypertension, diabetes mellitus, venous thrombo-embolic (VTE) disease, obstructive sleep apnea, and cancer amongst others. ${ }^{2}$ For most patients, bariatric surgery remains the only option for the treatment of obesity when dietary interventions and pharmacotherapy fail.

Amongst a range of bariatric surgical options currently in use includes [ Laparoscopic Sleeve Gastrectomy (LSG), and laparoscopic Roux-enY gastric bypass (LRYGB)], both of which have been shown to result in varying degrees of weight loss. ${ }^{3}$ However, there has been a rising incidence in complications associated with these procedures. Gastroesophageal reflux disease (GERD) in particular has been the subject of recent concerns. ${ }^{4}$ The prevalence of clinically relevant GERD associated with bariatric surgery is variable, but has been reported as ranging between $7 \%$ and $14 \% .{ }^{5-7}$ Uncertainty however remains regarding the exact evolution of symptoms especially among patients with different clinical phenotypes such as metabolic syndrome, obesity and multi-morbidities. In this Dose-Response Meta-Analysis (DRMA), we therefore intend to assess GERD symptoms over time with the view to clarify the timeframe of evolution of GERD symptoms among patients that have undergone these procedures.

\section{Materials And Methods}

\section{Database Search}

Literature search strategies was developed using medical subject headings (Mesh) and text key words related to bariatric surgery and GERD. The specific search strategies were created by a health sciences librarian with expertise in systematic reviews. Following the recommendations of the preferred reporting items for systematic reviews and meta-analyses (PRISMA) statement, ${ }^{8}$ a systematic literature search was performed using PubMed, Medline, EMBASE, Web of Science, and the Cochrane Library from inception to December 2018, combining the key words obesity, high BMI, weight loss and gastroesophageal reflux with bariatric surgery OR LSG OR laparoscopic sleeve gastrectomy OR sleeve gastrectomy OR SG OR LRYGB OR laparoscopic Roux-en-Y gastric bypass OR gastric bypass OR GB. Moreover, we individually observed the reference lists of the selected articles to find other potentially relevant studies. GERD was used as the observation 
index of outcome after all types of bariatric surgery (i.e., improvement of GERD after bariatric surgery or/and the number of cases of newly onset or worsened GERD after bariatric procedure). The means and measures of dispersion were approximated from the figures given in the reports.

\section{Selection of studies (Inclusion and exclusion criteria)}

Only clinical trials were included for this meta-analysis. The inclusion criteria were as follows: 1) studies reporting on the efficacy of LSG and/or LRYGB on GERD symptomatology; 2) new onset or worsening GERD after LSG and/or LRYGB. The exclusion criteria includes 1) studies with incomplete data for GERD symptoms following bariatric surgery ; 2) case series or case reports, 3) studies with follow-up periods of less than 6 months after bariatric surgery 4) Studies reporting in other languages other than English. Only the most relevant and comprehensive publications were included in the analysis to avoid duplicates, ambiguity; studies involving non-human subjects, or papers reporting data from the same study populations were excluded.

\section{Data Extraction}

A team of two investigators extracted the data using a standardized form, which was reviewed individually by a third investigator following analysis individually and in duplicate. To ensure standardization across the reviewers, a calibration exercise was carried out before starting the actual review. Any disagreement between reviewers was resolved by the consensus of two authors and the third reviewer. Data from each included study was extracted by two investigators and reviewed independently by a third investigator following essential indicators from each article into Table 1. These indicators included study author/year, study design, level of evidence, sample size, follow up period, type of bariatric surgery (LSG or LRYGB), GERD improvement rate, method of GERD evaluation, and study country.

\section{Quality Assessment}

The methodological quality of clinical trials was assessed by Cochrane Collaboration's tool for assessing risk bias which covers: sequence generation, allocation concealment, blinding, incomplete outcome data (e.g. drop-outs and withdrawals) and selective outcome reporting. ${ }^{9}$ The observational studies were assessed using the Newcastle-Ottawa Quality Assessment Scale (NOS) checklist. ${ }^{10}$

\section{Statistical analysis}

The effect size of interest was the difference in prevalence of GERD symptoms in patients immediately before and at any time point after bariatric surgery reported in the papers. This was modeled as a risk difference in a DRMA. The latter was conducted as a one-step procedure with time (as the "dose") along with change in risk as the outcome were fit into an inverse variance weighted non-linear robust error metaregression model, ${ }^{11}$ using restricted cubic splines with three knots in an effort to approximate the potential non-linear relationship. The weights were based on the inverse of the variance of the incremental risk difference in proportions of patients with GERD symptoms from the baseline at surgery. Stata MP 15 (StataCorp, College Station, TX) was used for the analysis, utilizing the remr package. ${ }^{12}$ Confidence level was set at $95 \%$.

\section{Results}

\section{Study Features}

A total of 32 studies including 43,994 patients (9547 in LSG and in 34447 LRYGB) were enrolled for the dose-response meta-analysis from a cluster of 2500 studies pooled from all databases. Figure 1 shows the flow chart of studies selection with details of retrieval process and filtering. The 32 selected studies were including nine prospective studies, and 23 retrospective observational studies ${ }^{13-44}$ They were conducted in 19 different countries (Argentina, Austria, Belgium, Canada, Chile, Colombia, France, Greece, India, Israel, Italy, Poland, Lebanon, Netherlands, Sweden, Switzerland, Taiwan, United Kingdom, USA) with clinical follow-up ranging from 6 months to 153 months after bariatric surgery. The demographic and clinical characteristics of the included studies are shown in Table 1.

\section{Effect of Bariatric Surgery on GERD}

A total of 32 studies (84.6\%) showed improvement or remission for obesity-related GERD (78.6\% in LSG, 100\% in LRYGB). The proportion of subjects with GERD symptoms at baseline was 23.1\% (IQR 12.0 - 34\%) and at follow-up was 8.8\% (IQR 2.8 - $13.6 \%$ ). While this seems to suggest a decrease in GERD symptoms after bariatric surgery, the follow-up varied considerably with a median of 24 months (IQR 12 - 60 months). When the incremental risk was modeled in a DRMA with time as the "dose" there was a decrease in prevalence of GERD symptoms till 2 years post-surgery and this gradually increased back to baseline at 4 years post-LSG surgery (Figure 2) and post-LRYGB surgery (Figure 3). The trend was a continuing increase in risk but the trend after 4 years was not reliable due to a paucity of data points. There was a much 
greater decrease after LRYGB compared to LSG, but this was driven by a single large study and after this was excluded, the trends were similar (Figure 4). In addition, there were fewer data-points for LRYGB.

\section{Discussion}

This meta-analysis represents the first comprehensive attempt at exploring the comparative prevalence of GERD symptoms following either LSG or LRYGB surgery. We found a significant decrease in GERD related symptoms up to two years following surgery. This symptomatic improvement was regardless of the type of surgery. Beyond two years however, uncertainty remains as to the impact of surgery on GERD related symptom relief. The rate of symptomatic improvement was steeper and relapse of symptoms quicker with LRYGB surgery compared with LSG procedures or be it with an uncertain point estimates. This has significant implication for patient counseling before surgery as well commissioning of surgical procedures. The exact mechanism underpinning the improvement in GERD symptoms following surgery continues to generate intense mechanistic debate. Several reports have attributed this to significant and durable weight reduction evident in patients who underwent these procedures. ${ }^{45,46}$

We found an unusually high prevalence of GERD symptoms at baseline before surgery. Previous reports have estimated this at $33 \% .{ }^{47}$ The difference in estimate from our review and that reported from previous studies may have to do with marked heterogeneity in the modalities employed to evaluate GERD. The change or improvement in GERD symptoms ( $\triangle$ GERD) from $23 \%$ at baseline to $8.8 \%$ over a median period of two years is comparable or better than that seen with anti-secretory therapy. ${ }^{48}$

The lack of difference in point estimates of residual GERD outcomes between SLG and LRYGB mirrors previous uncertainty regarding the exact impact of the type of bariatric surgery on GERD symptom improvement. The findings from the largest systematic review by Stenard et al exploring this uncertainty in patients who underwent LSG were discordant. ${ }^{49}$ About half of the studies in that review found symptomatic improvement in GERD symptoms following the procedure, with the remaining half showing signs of worsening GERD symptomatology. The apparent discordance in GERD outcomes in this review was attributable to heterogeneity in the mode of evaluation of GERD ranging from clinical evaluation, 24-hour ambulatory pH studies, esophageal manometry or contrast studies, to endoscopy. Additionally, only one study was prospective, the remaining studies were retrospective. Other subsequent reviews ${ }^{50,51}$ including that by Himpens et al ${ }^{52}$ also reported mixed outcomes regarding GERD symptoms improvement following LSG. Our review similarly found lack of superiority between different surgical modalities in GERD symptoms improvement following surgery. The confounding issues highlighted earlier including marked heterogeneity in the mode of evaluation of GERD may have accounted for our point estimates with regards to effect of bariatric surgical modality on GERD symptoms improvement.

Additionally, we found improvement in GERD symptoms plateauing at 4 years with significant uncertainty afterwards. Whilst this suggest need for more comprehensive studies to ascertain the exact impact of bariatric surgery in GERD symptoms beyond 4 years; it is probable that rapid weight gain reported from previous series may be the key driver to the is phenomenon.

\section{Strengths and limitation}

This DRMA represents the first comprehensive attempt at exploring the comparative efficacy of LRYGB vs. LSG surgical procedures in achieving sustained and durable improvement in GERD symptoms. It provides the first estimates of the average duration of GERD symptom improvement (2 years) following these procedures as well as raises the prospects for further studies to explore determinants of uncertainty in symptom relief after four years. As with previous systematic synthesis in this area, our DRMA is limited by differences in the modes of adjudication of GERD symptoms by various investigators. The reliance on clinical evaluation alone in some cases and paucity of data regarding utility of $\mathrm{PH}$ monitoring as well as endoscopy data in others may have accounted for the imprecision regarding some point estimates in previous studies (including ours).

\section{Conclusion}

In obese bariatric patients we found significant improvement in GERD symptoms at two years regardless of the type of bariatric surgery (LSG or LRYGB), but this is not sustained beyond four years. The rate of improvement in bariatric symptoms was faster but less durable with LRYGB compared to gastric sleeve surgery.

\section{Declarations}

\section{Acknowledgment}

We acknowledge the Qatar national library for accepting to cover the cost of publication of this review 


\section{Funding}

No infrastructural funding was received for this review.

\section{Author contribution}

A-NE: Review conceptualization, protocol registration, independent reviewer, risk of bias assessment, data interpretation, and writing of the initial draft/revision of the final manuscript

MID: Independent reviewer, risk of bias assessment, data interpretation, writing of the initial draft/revision of the final manuscript.

SD: Statistical data analysis, data interpretation, review of the initial and final manuscript drafts

M-AW: Protocol registration, data collection and curation

SS: independent reviewer, data collection and curation.

EH: Independent reviewer, revision of the final manuscript.

HS: Data collection, revision of final manuscript

MA: Data collection, revision of final manuscript

MS: Data collection, revision of final manuscript

\section{Conflict of interest}

None of the authors have any conflict of interest to declare

\section{References}

1. Kelly T, Yang W, Chen CS, Reynolds K, He J. Global burden of obesity in 2005 and projections to 2030. Int J Obes (Lond). 2008 Sep; 32(9):1431-37. Doi: 10.1038/ijo.2008.102

2. Apovian CM. Obesity: definition, comorbidities, causes, and burden. Am J Manag Care. 2016;22(7 Suppl):176-85.

3. Buchwald H, Avido Y, Braunwald E, et al. Bariatric surgery: s systematic review and meta-analysis. JAMA. 2004;292:1724-37.

4. Hampel H, Abraham NS, El-Serag HB. Meta-analysis: obesity and the risk for gastroesophageal reflux disease and its complications. Ann Intern Med. 2005;143:199-211.

5. Eusebi LH, Ratnakumaran R, Yuan Y, Solaymani-Dodaran M, Bazzoli F, Ford AC. Global prevalence of, and risk factors for, gastrooesophageal reflux symptoms: a meta-analysis. Gut. 2018;67(3):430-40.

6. Chang P, Friedenberg F. Obesity and GERD. Gastroenterol Clin North Am. 2014;43(1):161-73.

7. Erridge S, Moussa OM, Ziprin P, Darzi A, Purkayastha S. Risk of GERD-Related Disorders in Obese Patients on PPI Therapy: a Population Analysis. Obes Surg. 2018;28(9):2796-2803.

8. Moher D, Shamseer L, Clarke M, et al. Preferred reporting items for systematic review and meta-analysis protocols (PRISMA-P) 2015 statement. Syst Rev. 2015;4:1.

9. Green S, Higgins JPT, Alderson P, et al. Cochrane handbook for systematic reviews of interventions version 5.1.0 [updated March 2011]. The Cochrane Collaboration, 2011.

10. Stang A. Critical evaluation of the Newcastle-Ottawa scale for the assessment of the quality of nonrandomized studies in meta analyses. Eur J Epidemiol. 2010;25:603-5.

11. Xu C, Doi SAR. The robust error meta-regression method for dose-response meta-analysis. Int J Evid Based Healthc. 2018; 16(3):138144.

12. REMR: Stata module to implement robust error meta-regression method for dose-response meta-analysis. Furuya-Kanamori L, Xu C, Doi SA, editors. 2020///Jun. Boston College Department of Economics. Statistical Software Components.

13. Lakdawala MA, Bhasker A, Mulchandani D, Goel S, Jain S. Comparison Between the Results of Laparoscopic Sleeve Gastrectomy and Laparoscopic Roux-en-Y Gastric Bypass in the Indian Population: A Retrospective 1 Year Study. Obes Surg. 2010 Jan;20(1):1-6.

14. Langer FB, Bohdjalian A, Shakeri-Leidenmühler S, Schoppmann SF, Zacherl J, Prager G. Conversion from Sleeve Gastrectomy to Rouxen-Y Gastric Bypass: indications and outcome. Obes Surg. 2010 Jul;20(7):835-40. 
15. Omana JJ, Nguyen SQ, Herron D, Kini S. Comparison of comorbidity resolution and improvement between laparoscopic sleeve gastrectomy and laparoscopic adjustable gastric banding. Surg Endosc. 2010 Oct;24(10):2513-7.

16. Tai C-M, Huang C-K, Lee Y-C, Chang C-Y, Lee C-T, Lin J-T. Increase in gastroesophageal reflux disease symptoms and erosive esophagitis 1 year after laparoscopic sleeve gastrectomy among obese adults.. Surg Endosc. 2013 Apr;27(4):1260-1266. doi: 10.1007/s00464-0122593-9

17. Gluck B, Movitz B, Jansma S, Gluck J, Laskowski K. Laparoscopic Sleeve Gastrectomy is a Safe and Effective Bariatric Procedure for the Lower BMI (35.0-43.0 kg/m2) Population. Obes Surg. 2011 Aug;21(8):1168-71.

18. Chopra A, Chao E, Etkin Y, Merklinger L, Lieb J, Delany H. Laparoscopic sleeve gastrectomy for obesity: can it be considered a definitive procedure? Surg Endosc. 2012 Mar;26(3):831-7.

19. Ekelund M, Öberg S, Peterli R, Frederiksen SG, Hedenbro JL. Gastroesophageal Reflux after Vertical Banded Gastroplasty is Alleviated by Conversion to Gastric Bypass. Obes Surg. 2012 Jun;22(6):851-4.

20. Carabotti M, Silecchia G, Greco F, et al. Impact of Laparoscopic Sleeve Gastrectomy on Upper Gastrointestinal Symptoms. Obes Surg. 2013 Oct;23(10):1551-7.

21. Catheline J-M, Fysekidis M, Bachner I, et al. Five-year results of sleeve gastrectomy. J Viscer Surg. 2013 Nov;150(5):307-12.

22. Daes J, Jimenez ME, Said N, Dennis R. Improvement of Gastroesophageal Reflux Symptoms After Standardized Laparoscopic Sleeve Gastrectomy. Obes Surg. 2014 Apr;24(4):536-40.

23. Cecily E. D, Martin MJ. Laparoscopic Sleeve Gastrectomy in Patients With Preexisting Gastroesophageal Reflux Disease: A National Analysis. JAMA Surg. 2014 Apr 1;149(4):328-34.

24. Sharma A, Aggarwal S, Ahuja V, Bal C. Evaluation of gastroesophageal reflux before and after sleeve gastrectomy using symptom scoring, scintigraphy, and endoscopy. Surg Obes Relat Dis. 2014 Jul;10(4):600-5.

25. Burgerhart JS, Schotborgh CAI, Schoon EJ, et al. Effect of Sleeve Gastrectomy on Gastroesophageal Reflux. Obes Surg. 2014 Sep;24(9):1436-41.

26. Kular KS, Manchanda N, Rutledge R. Analysis of the Five-Year Outcomes of Sleeve Gastrectomy and Mini Gastric Bypass: A Report from the Indian Sub-Continent. Obes Surg. 2014 Oct;24(10):1724-8.

27. Boza C, Daroch D, Barros D, León F, Funke R, Crovari F. Long-term outcomes of laparoscopic sleeve gastrectomy as a primary bariatric procedure. Surg Obes Relat Dis. 2014 Nov;10(6):1129-33.

28. Sheppard CE, Sadowski DC, de Gara CJ, Karmali S, Birch DW. Rates of Reflux Before and After Laparoscopic Sleeve Gastrectomy for Severe Obesity. Obes Surg. 2015 May;25(5):763-8.

29. Gorodner V, Buxhoeveden R, Clemente G, Solé L, Caro L, Grigaites A. Does laparoscopic sleeve gastrectomy have any influence on gastroesophageal reflux disease? Preliminary results. Surg Endosc. 2015 Jul;29(7):1760-8.

30. Albanopoulos K, Tsamis D, Natoudi M, Alevizos L, Zografos G, Leandros E. The impact of laparoscopic sleeve gastrectomy on weight loss and obesity-associated comorbidities: the results of 3 years of follow-up. Surg Endosc. 2016 Feb;30(2):699-705.

31. Hendricks L, Alvarenga E, Dhanabalsamy N, Lo Menzo E, Szomstein S, Rosenthal R. Impact of sleeve gastrectomy on gastroesophageal reflux disease in a morbidly obese population undergoing bariatric surgery. Surgery Obes Related Dis. 2016 Mar;12(3):511-7.

32. Casella G, Soricelli E, Giannotti D, et al. Long-term results after laparoscopic sleeve gastrectomy in a large monocentric series. Surg Obes Relat Dis. 2016 May;12(4):757-62.

33. Angrisani L, Santonicola A, Hasani A, Nosso G, Capaldo B, lovino P. Five-year results of laparoscopic sleeve gastrectomy: effects on gastroesophageal reflux disease symptoms and co-morbidities. Surg Obes Relat Dis. 2016 Jun;12(5):960-8.

34. Aridi HD, Alami R, Tamim H, Shamseddine G, Fouani T, Safadi B. Long-term outcomes of laparoscopic sleeve gastrectomy: a Lebanese center experience. Surg Obes Relat Dis. 2016 Nov;12(9):1689-96.

35. Arman GA, Himpens J, Dhaenens J, Ballet T, Vilallonga R, Leman G. Long-term (11+years) outcomes in weight, patient satisfaction, comorbidities, and gastroesophageal reflux treatment after laparoscopic sleeve gastrectomy. Surg Obes Relat Dis. 2016 Dec;12(10):1778-86.

36. Parmar CD, Mahawar KK, Boyle M, Schroeder N, Balupuri S, Small PK. Conversion of Sleeve Gastrectomy to Roux-en-Y Gastric Bypass is Effective for Gastro-Oesophageal Reflux Disease but not for Further Weight Loss. Obes Surg. 2017 Jul;27(7):1651-8.

37. Garg H, Priyadarshini P, Aggarwal S, Agarwal S, Chaudhary R. Comparative study of outcomes following laparoscopic Roux-en-Y gastric bypass and sleeve gastrectomy in morbidly obese patients: A case control study. WJG. 2017;9(4):162.

38. Billing P, Stewart K, Billing J, et al. Sleeve gastrectomy improves GERD symptoms in 916 patients. Surgery Obes Relat Dis. 2017 Oct;13(10):S114. 
39. Chuffart E, Sodji M, Dalmay F, lannelli A, Mathonnet M. Long-Term Results After Sleeve Gastrectomy for Gastroesophageal Reflux Disease: a Single-Center French Study. Obes Surg. 2017 Nov;27(11):2890-7.

40. Goldenshluger M, Goldenshluger A, Keinan-Boker L, et al. Postoperative Outcomes, Weight Loss Predictors, and Late Gastrointestinal Symptoms Following Laparoscopic Sleeve J Gastrointest Surg. 2017 Dec;21(12):2009-15.

41. Borovicka J, Krieger-Grübel C, van der Weg B, et al. Effect of morbid obesity, gastric banding and gastric bypass on esophageal symptoms, mucosa and function. Surg Endosc. 2017 Feb;31(2):552-60.

42. Kowalewski PK, Olszewski R, Walędziak MS, et al. Long-Term Outcomes of Laparoscopic Sleeve Gastrectomy-a Single-Center, Retrospective Study. Obes Surg. 2018 Jan;28(1):130-4.

43. Berry MA, Urrutia L, Lamoza P, et al. Sleeve Gastrectomy Outcomes in Patients with BMI Between 30 and 35-3 Years of Follow-Up. Obes Surg. 2018 Mar;28(3):649-55.

44. Coupaye M, Gorbatchef C, Calabrese D, et al. Gastroesophageal Reflux After Sleeve Gastrectomy: a Prospective Mechanistic Study. Obes Surg. 2018 Mar;28(3):838-45.

45. De Groot NL, Burgerhart JS, Van De Meeberg PC, de Vries DR, Smout AJ, Siersema PD. Systematic review: the effects of conservative and surgical treatment for obesity on gastro-oesophageal reflux disease. Aliment Pharmacol Ther. 2009 Dec 1; 30(11-12):1091-102.

46. Howard DD, Caban AM, Cendan JC, et al. Gastroesophageal reflux after sleeve gastrectomy in morbidly obese patients. Surg Obes Relat Dis. 2011;7:709-13.

47. Althuwaini S, Bamehriz F, Aldohayan A, et al. Prevalence and Predictors of Gastroesophageal Reflux Disease After Laparoscopic Sleeve Gastrectomy. Obes Surg. 2018 Apr;28(4):916-22

48. Chiba N, De Gara CJ, Wilkinson JM, Hunt RH. Speed of healing and symptom relief in grade II to IV gastroesophageal reflux disease: a meta-analysis. Gastroenterology. 1997 Jun; 112(6):1798-810

49. Stenard, F., \& lannelli, A. Laparoscopic sleeve gastrectomy and gastroesophageal reflux. WJG. 2015;21(36),10348-10357. org/10.3748/wjg.v21.i36.10348

50. Chiu S, Birch DW, Shi X, Sharma AM, Karmali S. Effect of sleeve gastrectomy on gastroesophageal reflux disease: a systematic review. Surg Obes Relat Dis. 2011 Jul-Aug; 7(4):510-5

51. Oor JE, Roks DJ, Ünlü Ç, Hazebroek EJ. Laparoscopic sleeve gastrectomy and gastroesophageal reflux disease: a systematic review and meta-analysis. Am J Surg. 2016 Jan; 211(1):250-67.

52. Himpens J, Dapri G, Cadière GB. A prospective randomized study between laparoscopic gastric banding and laparoscopic isolated sleeve gastrectomy: results after 1 and 3 years.. Obes Surg. 2006 Nov; 16(11):1450-6.

\section{Table 1}

Table 1: Demographic and clinical characteristics of the included studies 


\begin{tabular}{|c|c|c|c|c|c|c|c|c|c|}
\hline Author, Year & $\begin{array}{l}\text { Surgery } \\
\text { Type }\end{array}$ & $\begin{array}{c}\text { Sample } \\
\text { size }\end{array}$ & $\begin{array}{l}\text { Patient } \\
\text { with } \\
\text { GERD }\end{array}$ & $\begin{array}{l}\text { GERD } \\
\text { improved } \\
\text { (N) }\end{array}$ & $\begin{array}{c}\text { GERD } \\
\text { not } \\
\text { improved } \\
(\mathrm{N}) \\
\end{array}$ & $\begin{array}{c}\text { GERD } \\
\text { Evaluation } \\
\text { Method(s) }\end{array}$ & $\begin{array}{l}\text { Follow- } \\
\text { up } \\
\text { (months) }\end{array}$ & Study Design & Country \\
\hline \multirow{2}{*}{$\begin{array}{c}\text { Lakdawala, } \\
2010\end{array}$} & LSG & 50 & 2 & 2 & 0 & \multirow[t]{2}{*}{ Symptoms } & \multirow[t]{2}{*}{12} & \multirow[t]{2}{*}{ Retrospective } & \multirow[t]{2}{*}{ India } \\
\hline & LRYGB & 50 & 6 & 6 & $\overline{0}$ & & & & \\
\hline Langer, 2010 & LRYGB & 3 & 3 & 3 & 0 & $\begin{array}{c}24 \text { hrs pH } \\
\text { manometry }\end{array}$ & 14 & Retrospective & Austria \\
\hline \multirow[t]{2}{*}{ Omana, 2010} & LSG & 49 & 9 & 2 & 7 & \multirow[t]{2}{*}{ Symptoms } & \multirow[t]{2}{*}{27} & \multirow[t]{2}{*}{ Retrospective } & \multirow[t]{2}{*}{$\overline{U S A}$} \\
\hline & LRYGB & 74 & 9 & 3 & 6 & & & & \\
\hline Tai, 2011 & LSG & 47 & 8 & 3 & 5 & Questionnaire & 12 & Prospective & Taiwan \\
\hline Gluck, 2011 & LSG & 204 & 113 & 112 & 1 & Questionnaire & 36 & Retrospective & USA \\
\hline Chopra, 2012 & $\begin{array}{l}\text { LSG } \\
\end{array}$ & 174 & 24 & 11 & 13 & $\begin{array}{l}\text { Symptoms \& } \\
\text { endoscopy }\end{array}$ & 6 & Retrospective & USA \\
\hline Ekelund, 2012 & LRYGB & 5 & 5 & 5 & 0 & $\begin{array}{c}\text { Endoscopy \& } \\
24 \text { hrs pH } \\
\text { manometry }\end{array}$ & 1.5 & Prospective & Sweden \\
\hline $\begin{array}{c}\text { Carabotti, } \\
2013\end{array}$ & LSG & 74 & 20 & 13 & 7 & Questionnaire & 47 & Retrospective & Italy \\
\hline $\begin{array}{l}\text { Catheline, } \\
2013\end{array}$ & LSG & 45 & 5 & 0 & 5 & $\begin{array}{l}\text { Symptoms \& } \\
\text { endoscopy }\end{array}$ & 60 & Retrospective & France \\
\hline Daes, 2013 & LSG & 382 & 170 & 160 & 10 & $\begin{array}{c}\text { Symptoms \& } \\
\text { endoscopy }\end{array}$ & 22 & Prospective & Colombia \\
\hline Cecily, 2014 & LSG & 4832 & 2148 & 341 & $\frac{1807}{6347}$ & Symptoms & 6 & Retrospective & USA \\
\hline Sharma 2014 & LSG & $\frac{33801}{32}$ & $\frac{17002}{8}$ & $\frac{10113}{5}$ & 3 & Questionnaire & 12 & Prospective & India \\
\hline $\begin{array}{c}\text { Burgerhart, } \\
2014\end{array}$ & LSG & 20 & 14 & 6 & 8 & $\begin{array}{c}\text { Questionnaire, } \\
24 \mathrm{hrs} \text { pH } \\
\text { manometry }\end{array}$ & 3 & Prospective & Netherlands \\
\hline \multirow[t]{2}{*}{ Kular, 2014} & LSG & 76 & 6 & 2 & 4 & \multirow[t]{2}{*}{ Symptoms } & \multirow[t]{2}{*}{60} & \multirow[t]{2}{*}{ Retrospective } & \multirow[t]{2}{*}{ India } \\
\hline & LRYGB & 72 & 5 & 3 & 2 & & & & \\
\hline Boza, 2014 & LSG & 161 & 7 & 0 & 7 & Questionnaire & 60 & Retrospective & Chile \\
\hline \multirow{2}{*}{$\begin{array}{l}\text { Sheppard, } \\
2015\end{array}$} & $\begin{array}{l}\text { LSG } \\
\text { DYCP }\end{array}$ & 205 & 44 & 3 & 41 & \multirow[t]{2}{*}{ Symptoms } & \multirow[t]{2}{*}{12} & \multirow[t]{2}{*}{ Retrospective } & \multirow[t]{2}{*}{ Canada } \\
\hline & LRYGB & 173 & 30 & 15 & 15 & & & & \\
\hline $\begin{array}{l}\text { Gorodner, } \\
2015\end{array}$ & LSG & 14 & 4 & 0 & 4 & $\begin{array}{l}24 \text { hrs pH } \\
\text { manometry }\end{array}$ & 12 & Prospective & Argentina \\
\hline $\begin{array}{c}\text { Albanopoulus, } \\
2016\end{array}$ & LSG & 88 & 24 & 16 & 8 & $\begin{array}{l}\text { Symptoms \& } \\
\text { endoscopy }\end{array}$ & 36 & Retrospective & Greece \\
\hline $\begin{array}{c}\text { Hendricks, } \\
2016\end{array}$ & LSG & 919 & 13 & 0 & 13 & $\begin{array}{l}\text { Symptoms, } \\
\text { endoscopy, } \\
24 \text { hrs pH } \\
\text { manometry }\end{array}$ & 78 & Retrospective & USA \\
\hline Casella, 2016 & LSG & 148 & 27 & 19 & 8 & $\begin{array}{l}\text { Symptoms \& } \\
\text { endoscopy }\end{array}$ & 72 & Retrospective & Italy \\
\hline $\begin{array}{l}\text { Angrisani, } \\
2016\end{array}$ & LSG & 105 & 26 & 15 & 11 & $\begin{array}{c}\text { Symptoms \& } \\
\text { endoscopy }\end{array}$ & 60 & Retrospective & Italy \\
\hline Aridi, 2016 & LSG & 76 & 17 & 8 & 9 & Symptoms & 60 & Retrospective & Lebanon \\
\hline Arman, 2016 & LSG & 65 & 7 & 0 & 7 & Symptoms & 153 & Retrospective & Belgium \\
\hline Parmar, 2017 & LRYGB & 22 & 10 & 10 & 0 & Symptoms & 24 & Prospective & UK \\
\hline Garg, 2017 & LRYGB & 40 & 7 & 7 & 0 & Questionnaire & 24 & Retrospective & USA \\
\hline & LSG & 40 & 4 & 2 & 2 & & & & \\
\hline Billing, 2017 & LSG & 916 & 142 & 76 & 66 & Questionnaire & 12 & Retrospective & USA \\
\hline Chuffart, 2017 & LRYGB & 7 & 2 & 2 & 2 & Symptoms \& & 72 & Retrospective & France \\
\hline & LSG & 41 & 13 & 4 & 9 & endoscopy & & & \\
\hline $\begin{array}{c}\text { Goldenshluger, } \\
2017\end{array}$ & LSG & 178 & 28 & 17 & 11 & Symptoms & 36 & Retrospective & Israel \\
\hline $\begin{array}{c}\text { Borovicka, } \\
2017 \\
\end{array}$ & LRYGB & 134 & 48 & 17 & 38 & Endoscopy & 7.5 & Prospective & Switzerland \\
\hline $\begin{array}{c}\text { Kowalewski, } \\
2017\end{array}$ & LSG & 100 & 4 & 0 & 4 & Symptoms & 96 & Retrospective & Poland \\
\hline Berry, 2018 & LSG & 477 & 121 & 78 & 43 & $\begin{array}{c}\text { Symptoms \& } \\
\text { endoscopy }\end{array}$ & 36 & Retrospective & Chile \\
\hline Coupaye, 2018 & LSG & 47 & 16 & 10 & 6 & $\begin{array}{l}24 \mathrm{hrs} \mathrm{pH} \\
\text { manometry }\end{array}$ & 12 & Prospective & France \\
\hline
\end{tabular}


GERD, Gastroesophageal Reflux Disease; LSG, Laparoscopic Sleeve Gastrectomy; LRYGB, Laparoscopic Roux-en-Y gastric bypass surgery; USA, United State of America, UK, United Kingdom

\section{Figures}

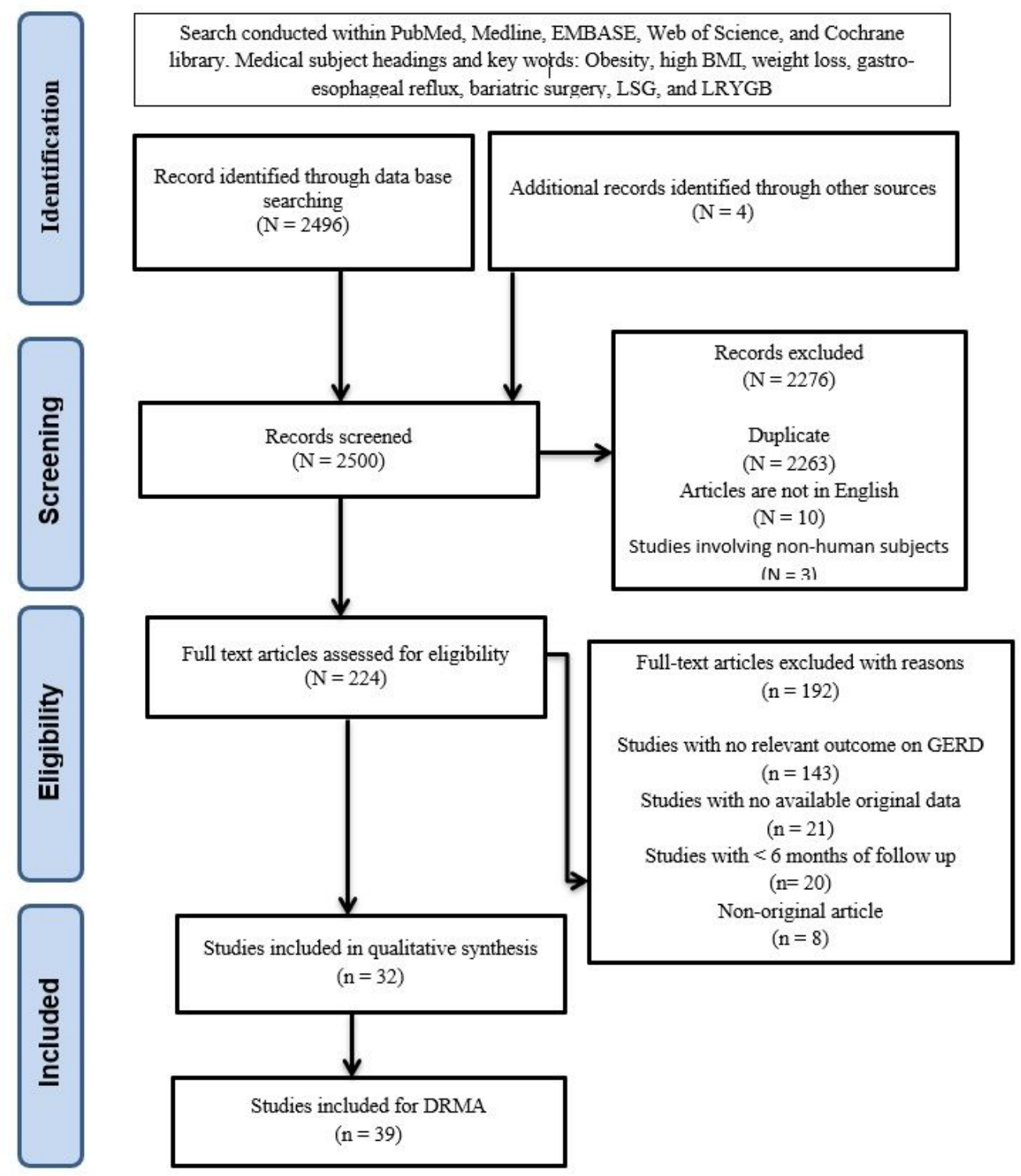

Figure 1

Flow chart of literature search 


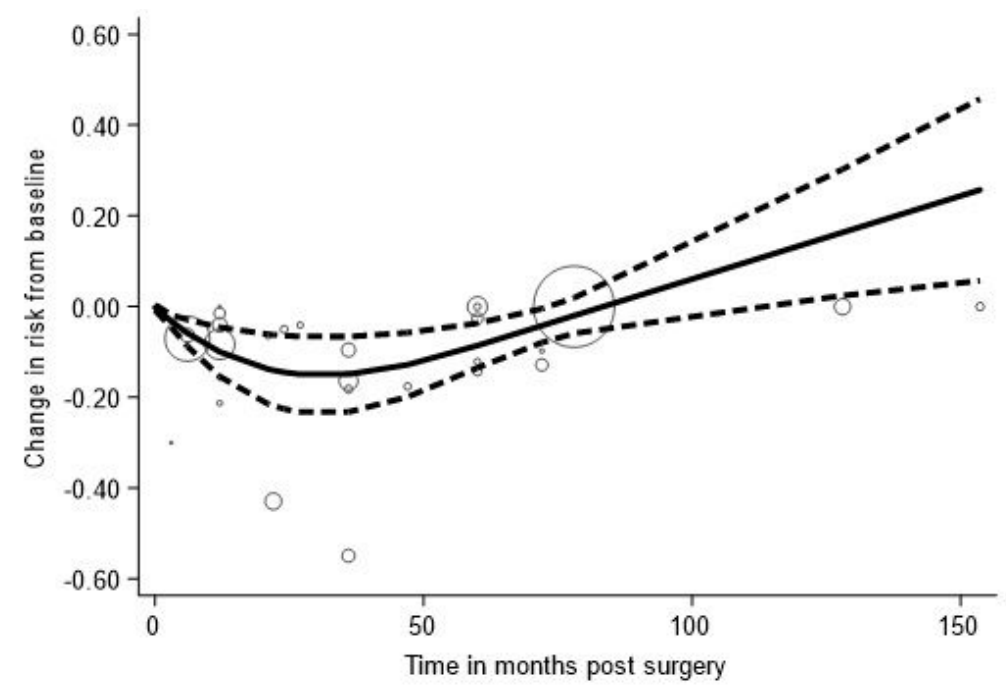

\section{Figure 2}

Laparoscopic Sleeve Gastrectomy (LSG) DRMA results. The figure depicts difference in prevalence from baseline over time of GERD symptoms. Dashed lines depict the $95 \%$ confidence intervals

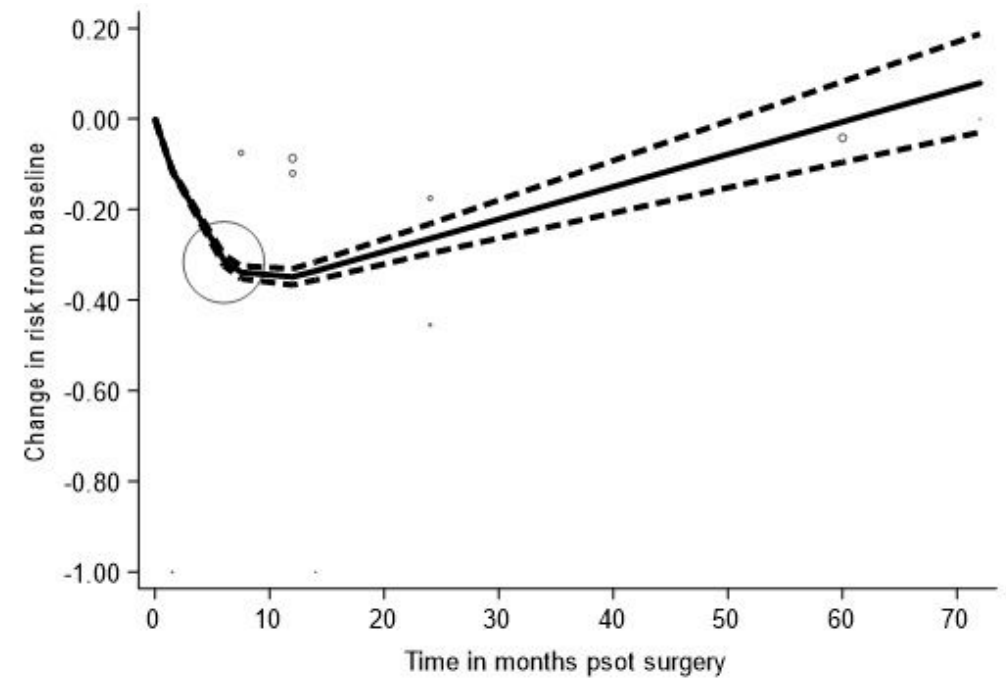

\section{Figure 3}

Laparoscopic Roux-en-Y gastric bypass (LRYGB) DRMA results. The figure depicts difference in prevalence from baseline over time of GERD symptoms. Dashed lines depict the $95 \%$ confidence intervals 


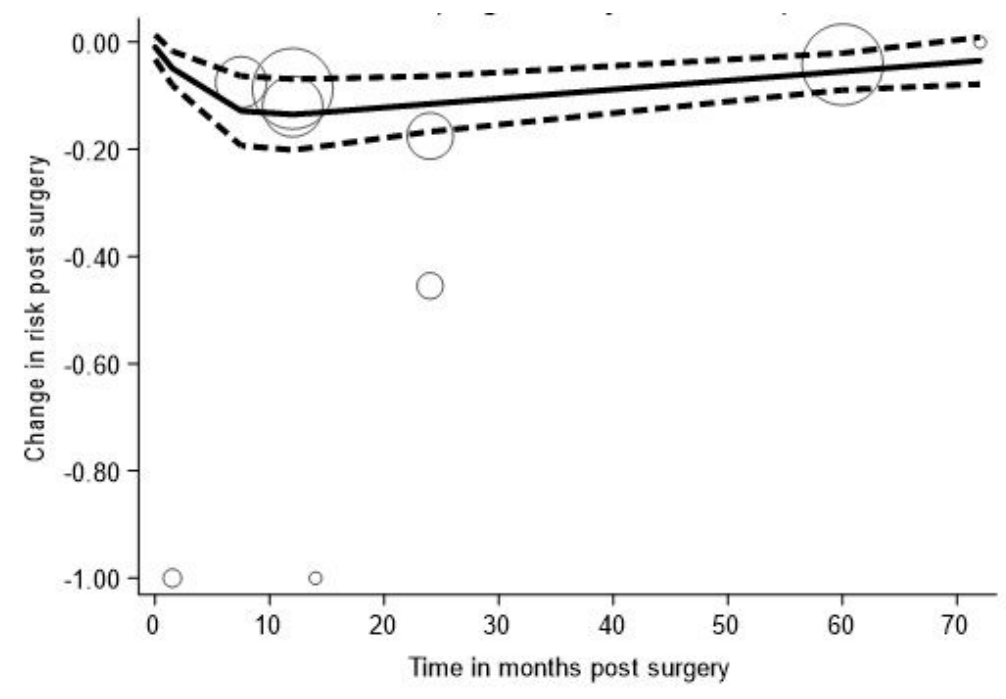

\section{Figure 4}

Laparoscopic Roux-en-Y gastric bypass (LRYGB) DRMA results after exclusion of a single large study. The figure depicts difference in prevalence from baseline over time of GERD symptoms. Dashed lines depict the $95 \%$ confidence intervals 